\title{
Finite Element Analysis of Concrete Damage in Sticked Side-plated Reinforced Concrete Beam
}

\author{
He Huang ${ }^{1}$, Chuanlong Zou ${ }^{1}$, Xiaoguang Liang ${ }^{1}$, Shan Chen ${ }^{1, a}$, Mingmao Li $^{1}$ \\ ${ }^{1}$ College of Civil Engineering and Architecture, Nanning University, 530200, Nanning City, Guangxi Province, P.R.China.
}

\begin{abstract}
In order to study the concrete damage in sticked side-plated reinforced concrete beam under static load, a common reinforced concrete beam and a sticked side-plated reinforced concrete beam were designed to conduct finite element comparison experiments. The results show that compared with ordinary reinforced concrete beams, the bearing capacity of sticked side-plated reinforced concrete beam is significantly improved, and the range of concrete tensile damage is significantly reduced. It further verifies that the sticked side-plated reinforced method is effective in reducing concrete tensile damage.
\end{abstract}

\section{Introduction}

At present, the commonly used reinforcement methods for reinforced concrete beams mainly include the Sticked Side-plated method [1], the enlarged section method ${ }^{[2]}$, the external prestress method ${ }^{[3]}$ and the steel plateconcrete combination reinforcement (SPSS) method ${ }^{[4]}$. Where, the paste steel plate method has been widely researched and applied due to its advantages such as simple and easy to use and greatly improved bending strength. Wang M R ${ }^{[5]}$ established a formula for calculating the ultimate bearing capacity of the normal section based on the proper reinforcement failure of a reinforced concrete $\mathrm{T}$-section beam strengthened with a steel plate. Zhang $\mathrm{W} \mathrm{Z}^{[6]}$ used the method of the paste steel plate to strengthen the cross section of a reinforced concrete beam with a corrosion rate of $8 \%$, and then finite element analysis showed that the bearing capacity of the strengthened beam was significantly increased, and the yield deflection was not changed significantly. Zhang Y N ${ }^{[7]}$ designed 8 steel plate-reinforced box concrete beams with different parameters, and conducted bending tests, which showed that steel plate reinforcement can well improve the bending performance of the beam. Mao D $\mathrm{J}^{[8]}$ introduced the coefficient $\delta$ based on the secondary stress characteristics of reinforced concrete beams strengthened with steel plates, and put forward the calculation formula of the relative limit compression zone height $\xi \mathrm{b}$ after reinforcement. Song $\mathrm{L}^{\left[{ }^{[9]}\right.}$ studied the flexural performance of $\mathrm{RC}$ beams strengthened with steel plates under secondary stress, and the results show that the use of steel plates to strengthen RC beams under secondary stress can enhance the flexural capacity of the beams. Li L Z ${ }^{[10]}$ put forward a piecewise linear simplified model that can be used to calculate lateral slip and lateral shear force transmission through experimental analysis and comparative analysis of reinforced concrete beams reinforced with steel plates anchored on the beam side. Cai Z W ${ }^{[11]}$ studied the shear performance of beam-side anchored steel plate strengthened concrete beams through design comparison experiments and showed that the beam-side anchored steel plate method can effectively improve the shear capacity of concrete beams. Wu Z L ${ }^{[12]}$ was based on the experimental research on the shear performance of concrete beams strengthened with four beam side anchored steel plates, and used the finite element software OpenSees to analyze the full process of loading and the mechanical performance of the members under shear failure.

This paper takes the sticked side-plated reinforced concrete beam as the research object, compares and analyzes with ordinary reinforced concrete beam, and calculates and analyzes the concrete damage law of reinforced concrete beam under concentrated load based on the finite element analysis software ABAQUS.

\section{Research of model design}

\subsection{Model design}

In order to study the influence of the sticked side-plate on the damage of reinforced concrete beams, a comparative experiment was designed. Two beams were designed, one is ordinary reinforced concrete beam (RCB), and the other is sticked side-plated reinforced concrete beam (SSRCB) with steel plate attached to the side. The RCB is $4600 \mathrm{~mm}$ long, the distance from the centerline of the bottom support is $4500 \mathrm{~mm}$, the distance from the loading point to the centerline of the support is 1500 , the beam section size is $450 \times 180 \mathrm{~mm} 2$, and the thickness of the concrete protective layer is $20 \mathrm{~mm}$.

According to the principle that when a simply supported beam is subjected to a concentrated force at the third-equal point, the bending moment of the beam is

a Corresponding author: 346201114@qq.com 
reflected as large in the middle and small at both ends, and the shear force is reflected as large at both ends and zero in the middle. Designed as a trough type. Specifically: on the basis of the RCB beam, the method of sticking steel plates on both sides of the longitudinal section of the beam was adopted. The steel plates at both ends were designed to be spread along the longitudinal plane of the beam, and the height was flush with the height of the beam. The bottom of the beam was pasted, and the height was $1 / 3$ of the beam height. The schematic diagram of RCB and SSRCB is shown in Figure 1.
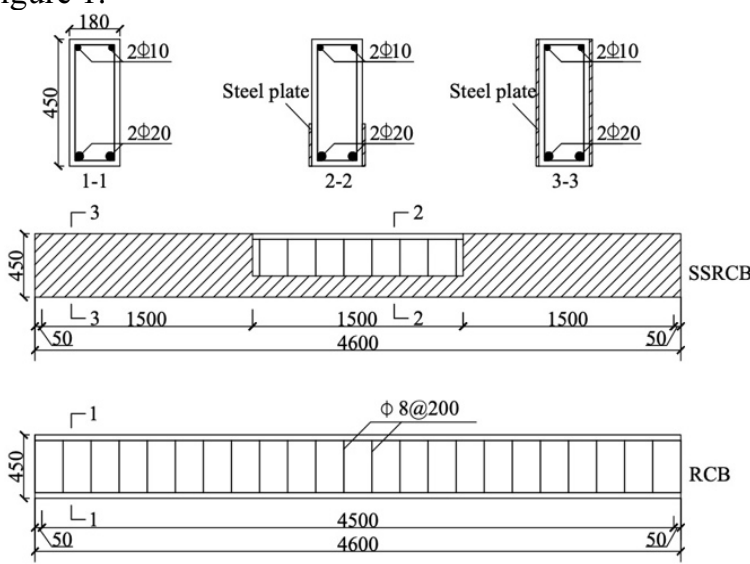

Figure 1. Schematic diagram of model structure

\subsection{Material parameters and research assumptions}

The longitudinal steel bars at the bottom of the beam are HRB335 steel bars with a yield point strength of $335 \mathrm{MPa}$ and a diameter of $20 \mathrm{~mm}$. The erecting steel bars at the top of the beam are also HRB335 steel bars with a diameter of $10 \mathrm{~mm}$. The stirrups are made of HPB300 steel bars, the yield point strength is $300 \mathrm{MPa}$, the diameter is $8 \mathrm{~mm}$, and the stirrup spacing is $200 \mathrm{~mm}$.

The strength grade of the steel plate is Q235, the yield point strength is $235 \mathrm{MPa}$, and the thickness is $2 \mathrm{~mm}$. The mass density of the steel is $7.80 \mathrm{E}-9 \mathrm{t} / \mathrm{mm} 3$, the modulus of elasticity is $210000 \mathrm{MPa}$, and the Poisson's ratio is 0.3 . The concrete strength grade is $\mathrm{C} 25$, the mass density is $2.30 \mathrm{E}-9 \mathrm{t} / \mathrm{mm} 3$, the elastic modulus is 15427.3MPa, and the Poisson's ratio is 0.18 .

Assuming that steel plates and steel bars are ideal linear elastic and ideal elastoplastic materials, the bond slip between the two and the concrete is not considered.

\subsection{Build a finite element model}

According to the designed size parameters and material parameters of RCB and SSRCB, the model was built using ABAQUS software, and the model is shown in Figure 2. In order to facilitate the calculation, a vertical downward displacement load was applied to the model with a size of $5 \mathrm{~cm}$.

The experiment was carried out in the Civil Engineering Laboratory of Nanning University. The instrument was a YE-2000C Pressure Testing Machine with a maximum loading load of $2000 \mathrm{kN}$ and a loading speed of $0.3 \mathrm{MPa} / \mathrm{s}$. The test equipment is shown in Figure 3.

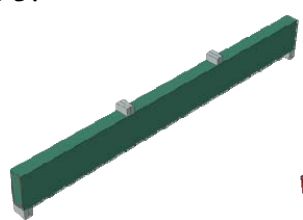

(a) $\mathrm{RCB}$

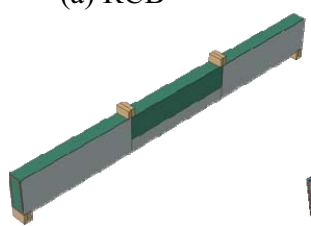

(c) SSRCB

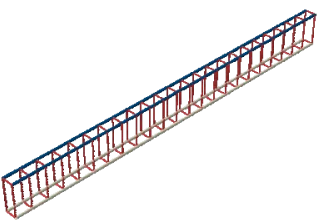

(b) Rebars of RCB

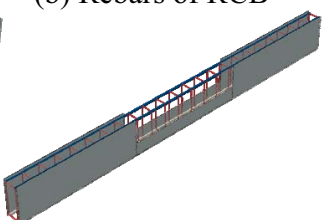

(d) Rebars of SSRCB
Figure 2. Structural diagram

\section{Results analysis and discussion}

\subsection{Analysis of the relationship between force and displacement}

The displacement of the center position of the loading point on one side of the two models and the support reaction force at the support were taken, and drew the force-displacement relationship curve after data processing, as shown in Figure 3. As can be seen from the figure, for the RCB model, when the loading displacement is $20.04 \mathrm{~mm}$, the maximum load at the loading point is $166.27 \mathrm{kN}$, while for the SSRCB model, the maximum load at the loading point is $357.87 \mathrm{kN}$ when the loading displacement is $27.36 \mathrm{~mm}$. It is more than twice that of the RCB model. The results show that sticking steel plates on the sides of concrete beams can improve the bearing capacity of concrete beams.

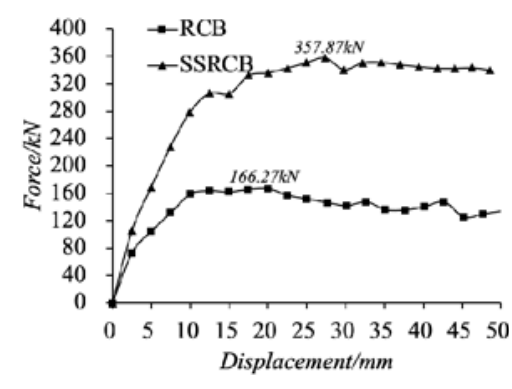

Figure 3. Loading-displacement curve

\subsection{Stress analysis}

The S-Mises stress diagram of each model was obtained after the displacement is loaded with $50 \mathrm{~mm}$ as shown in the figure. It can be seen from Figure 4(a) that for the RCB model, the maximum stress of the beam is $16.87 \mathrm{MPa}$, and the concrete stress near the loading point is about $12.67 \mathrm{MPa}$, showing a tendency of oblique failure from the loading point to the support.

It can be seen from Figure 4(b) that for the SSRCB reinforced with $2 \mathrm{~mm}$ steel plate, after the steel plate was hidden, the maximum stress of the beam was $42.85 \mathrm{MPa}$, which appears at the support and loading point. The 
stress between the two loading points was about $21.43 \mathrm{MPa}$. At the same time, there was a tendency of oblique failure between the support and the loading point. If the steel plate was retained (Figure 4(c)), the stress of the steel plate in the middle of the beam reaches the yield strength of the steel plate $235 \mathrm{MPa}$. At the same time, the stress of the steel plate at the support and the loading point was also close to the yield strength of the steel plate. The results show that under the same displacement load, adding lateral steel plates to strengthen the concrete beam can increased the stress intensity of the concrete beam.

\subsection{Concrete damage analysis}

Concrete damage is mainly divided into tensile damage and compression damage. The tensile damage cloud

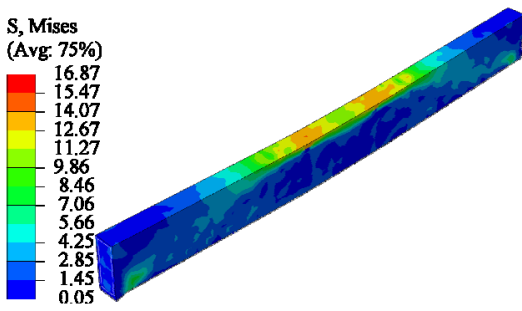

(a)

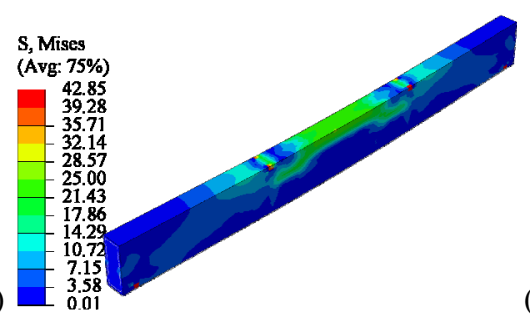

(b)

diagram of each model under displacement load is shown in Figure 5. It can be seen from Figure 5(a) that for the RCB model, the concrete damage between the two loading points is the most obvious, and the damage develops from bottom to top, almost reaching the top of the beam. The concrete damage between the support, the loading point and the bottom surface of the beam corresponding to the loading point presents a triangular shape, i.e, the damage gradually increases from the support to the loading point, and almost becomes a slowly rising oblique line, the closer it is to the loading point, The larger the damage area; at the same time, since the interface between the support and the bottom of the concrete is connected in a tie manner during modeling, the partial tensile damage of the concrete on the upper part of the support can be ignored.

Figure 4. Stress diagram of the model after loading

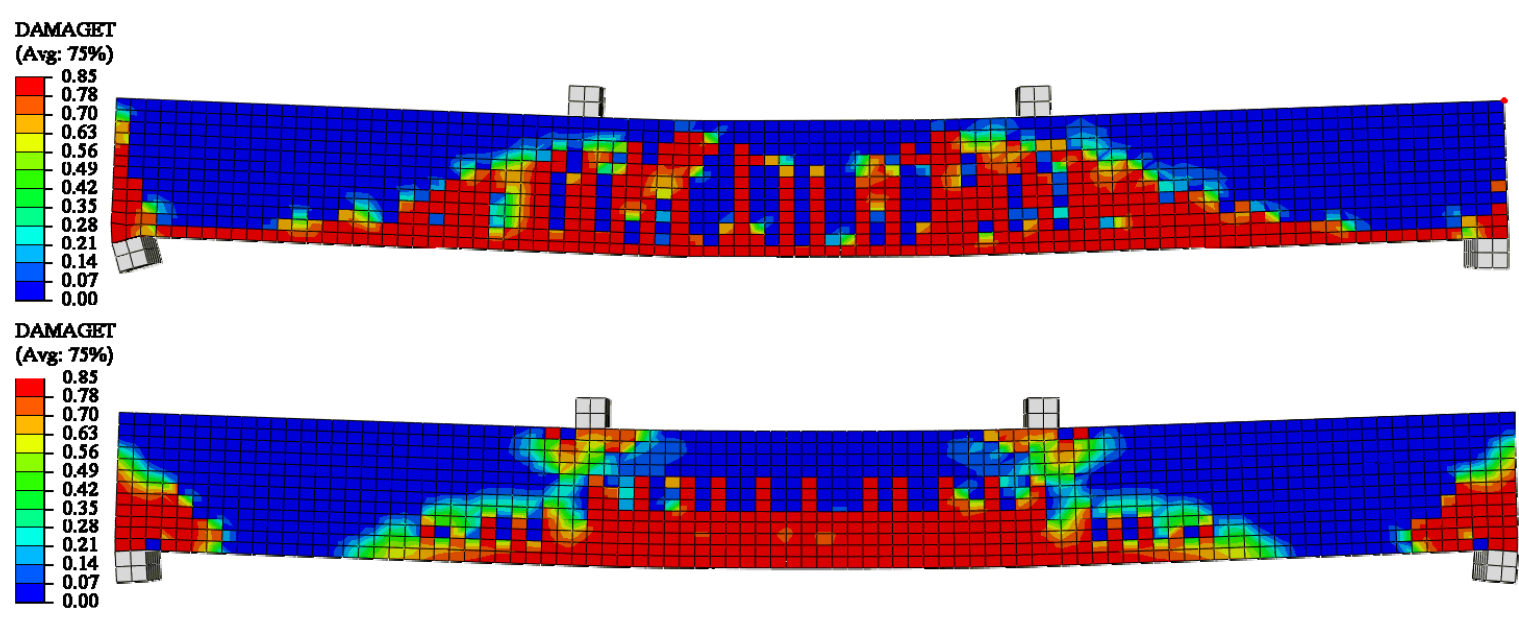

Figure 5. Concrete tensile damage: (a) RCB (b) SSRCB

In order to make a better comparison, the steel plate in the SSRCB model was hidden, and only the damage of the concrete beam (Figure 5(b)) was displayed. It can be seen that the concrete damage between the two loading points was the most obvious. The damage developed from bottom to top, and was densest in the middle of the beam. The height of part of the damage reached almost $2 / 3$ of the beam height. In addition, the area at the bottom of the beam corresponding to the two loading points also showed a phenomenon that part of the concrete damage developed to the two supports. The concrete damage of the bearing and the loading point was divided into two parts. One part was mainly caused by the partial concrete damage near the two loading points. The damage developed from top to bottom, and the height was about $1 / 4$ of the beam height; the other part was the support. The triangle-shaped area above the seat, the damage was caused by the connection method of tie. Part of the concrete near the support between the loading point and the support has no damage. The results show that: compared to the RCB model, the SSRCB model with steel plates attached for reinforcement, the concrete damage range is generally smaller than that of the RCB model, especially the upward damage degree of the mid-span concrete and the extent of the mid-span damage spreading to both sides are much smaller than the RCB model It further shows that pasting steel plates has a good effect on reducing concrete damage.

The compressed damage cloud diagram of each model under displacement load is shown in the figure. It can be seen from Figure 6 that for the RCB model, the compression damage of the concrete mainly occurs at the positions of the two ends of the support. In addition, part of the compression damage occurs at the bottom of the 
beam relatively in the middle between the loading point and the support. For the SSRCB model, on the one hand, the concrete compression damage appears at the support, and the degree of damage is greater than that of the RCB model. The damage is caused by the SSRCB support $(357.87 \mathrm{kN})$ being larger than the RCB $(166.27 \mathrm{kN})$; at the loading point, Obvious downward expansion of compression damage also appeared, and the height was

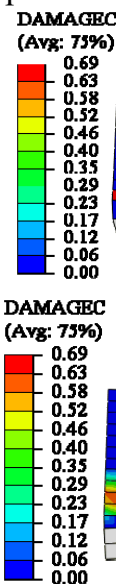

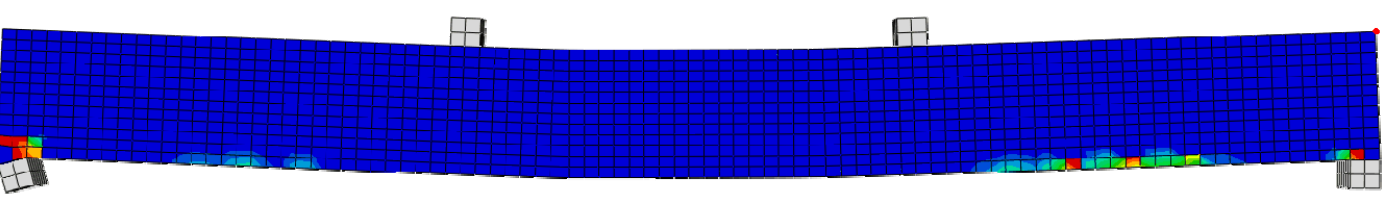
C

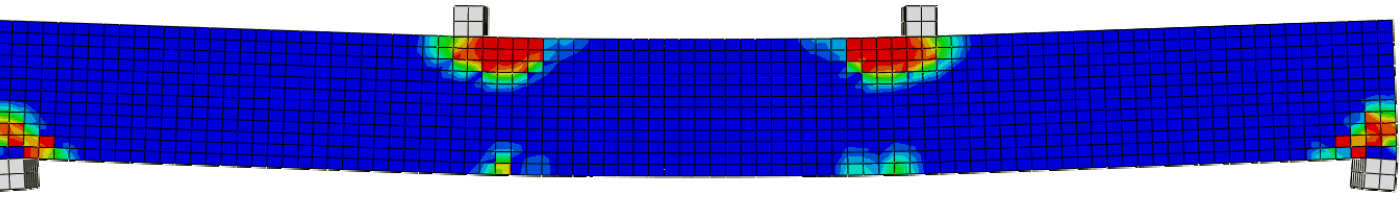

(a)

Figure 6. Compression damage of concrete: (a) RCB (b) SSRCB almost close to $1 / 3$ of the beam height. The damage was also caused by the larger force on the SSRCB loading point than the RCB. At the same time, the position of the bottom of the beam corresponding to the damage position also began to show a certain degree of damage. The results show that the increase of the loading load is likely to cause the increase of the compression damage of the loading point and the support.

\section{Conclusion}

In order to study the concrete damage in sticked sideplated reinforced concrete beam under static load, a finite element comparative analysis was carried out, and the following conclusions were obtained:

(1) Compared with ordinary reinforced concrete beams, the bearing capacity of the sticked side-plated reinforced concrete beam is higher, but it is prone to increase the compression damage of the support and the loading point of the concrete while bearing a larger load.

(2) Compared with ordinary reinforced concrete beams, the concrete tensile damage range of the sticked side-plated reinforced concrete beam is smaller.

\section{Acknowledgments}

This research was funded by Nanning Excellent Young Scientist Program and Guangxi Beibu Gulf Economic Zone Major Talent Program (RC20190208), Scientific Research Team Project of Nanning University (2018KYTD04), and Professor Cultivation Project of Nanning University (2018JSGC14).

\section{References}

1. Peng J X, Li J, Tang H, Zhang J R. Experimental analysis of strengthening effect of corroded reinforced concrete beams strengthened with bolted steel plates. Journal of Civil. Architectural \& Environmental Enginering.37(1): 88-95. (2015).

2. Huang J F, Zhu C M, Gong Z G, Zhang F W. Experimental study on seismic behavior of earthquake-damaged RC frame strengthened by enlarging cross-section. China Civil Engineering Journal.45(12): 9-17. (2012).

3. Li L, Jin L Z, Zhu W X, Tian A J. Analysis of the deflection of reinforced concrete simple beam reinforcement using external pre- stressing force. Concrete. 12: 51-53. (2010).

4. Wang J J, Tao M X, Zhou M, et, al. Force transfer mechanism in RC beams strengthened in shear by means of steel plated concrete. Engineering Structures, 171: 56-71. (2018).

5. Wang M R. Calculation of Flexural Capacity of Reinforced Concrete of Beam Strengthened with Bonded Steel Plates Considering Stage Loading. Science Technology and Engineering.14(6): 49-53. (2014).

6. Zhang $\mathrm{W}$ Z. Fea Analysis of Mechanical Performance of RC Beams Strengthened with Bonded Steel Plate Based on ABAQUS Software. Journal of Jilin Jianzhu University.34(5): 17-20. (2017).

7. Zhang Y N, Li C Y, Liu J S, et al. Experimental study on flexural performance of box type concrete beams strengthened with steel plate. Chinese Journal of Applied Mechanics, 32 (6):1031-1037. (2015).

8. Mao D J. Effect of secondary load on reinforced concrete beam strengthened by bonding steel plates considering the cracking. Journal of Hefei University of Technology, 38(5): 664-668. (2015).

9. Song L, Li L G, Fan C. Analysis for bending resistance of RC beams reinforced with bonded steel plates under secondary stress. Journal of Shenyang University of Technology, http://kns.cnki.net/kcms/detail/21.1189.t.20191121.0 854.002.html. (2019). 
10. Li L Z, Jiang C J, Lu Z D, Su Ray K L. Transfer Model of Transverse Shear in Bolted Side-plated Reinforced Concrete Beams. Journal of Hunan University (Natural Sciences). 43(3): 113-119. (2016).

11. Cai Z W, Lu Z D, Li L Z, et al. Experimental study on shear performance of bolted side-plated reinforced concrete beams. Journal of Zhejiang University (Engineering Science). 52(1): 82-88. (2018).

12. Wu Z L, Lu Z D, Li L Z, Zhang J X. Non-linear Finite Element Analysis of Bolted Side-plated Beams. Journal of Tongji University (Natural Science). 47(7): 906-913. (2019). 